\title{
Association between neurological injury and the severity of oropharyngeal dysphagia after stroke
}

\section{Original Article}

\section{Artigo Original}

\author{
Danielle Martins 0tto ${ }^{1}$ \\ Marlise de Castro Ribeiro', \\ Liselotte Menke Barea ${ }^{1,2}$ \\ Renata Mancopes ${ }^{3}$ \\ Sheila Tamanini de Almeida ${ }^{1}$
}

\begin{abstract}
Purpose: To associate the degree of biomechanical impairment in the swallowing process with the severity (National Institute of Health Stroke Scale - NIHSS) and type of neurological injury in patients post stroke. Methods: A cross-sectional, descriptive study conducted with 42 patients ( 22 females), aged 65.7 years on average diagnosed with stroke. All patients underwent clinical neurological evaluation and application of the NIHSS in the first 48 hours after stroke. The swallowing function was evaluated using the Functional Oral Intake Scale (FOIS) and the Protocol for the Investigation of Oropharyngeal Dysphagia in Adults. The Fisher's Exact Probability Test was used to assess the correlation between the degree of swallowing impairment and the severity (NIHSS score) and type of stroke. The study results were statistically analyzed at $5 \%$ significance level $(p \leq 0.05)$. Results: $92.9 \%$ of the patients presented ischemic stroke; $59.5 \%$ presented impairment of the anterior cerebral circulation. Statistically significant correlation was found between the neurological scale (NIHSS) scores and the swallowing impairment scale $(p=0.016)$. Conclusion: An association between stroke severity and oropharyngeal dysphagia severity was observed. A high proportion of patients with ischemic stroke with circulation affected in the anterior cerebral region presented severe oropharyngeal dysphagia. No statistically significant correlation was observed between the FOIS scale and stroke severity.
\end{abstract}

\footnotetext{
Study carried out at public infirmary of the hospital Irmandade Santa Casa de Misericórdia de Porto Alegre - Porto Alegre (RS), Brazil.

${ }^{1}$ Universidade Federal de Ciências da Saúde de Porto Alegre - UFCSPA - Porto Alegre (RS), Brazil.

${ }^{2}$ Irmandade Santa Casa de Misericórdia de Porto Alegre - ISCMPA - Porto Alegre (RS), Brazil.

${ }^{3}$ Universidade Federal de Santa Maria - UFSM - Santa Maria (RS), Brazil.

Financial support: nothing to declare.

Conflict of interests: nothing to declare.
}

Correspondence address:

Sheila Tamanini de Almeida Rua Sarmento Leite, 245, Porto Alegre (RS), Brazil, CEP: 90050-170. E-mail: sheilat@ufcspa.edu.br

Received: May 07, 2015

Accepted: November 22, 2015 


\section{INTRODUCTION}

Oropharyngeal dysphagia (OD) is defined as impaired swallowing that affects the upper throat and may hinder the ability to ingest food. The biomechanical events involved in swallowing occur synchronously and cooperatively, with the performance of the following phase dependent on the previous phase, as well as involve the integrity of the orofacial, muscular, nerve and cerebral cortex structures. Neurogenic dysphagia is a disorder caused by disease or neurological trauma which may affect the muscular action responsible for the transport of the bolus from mouth to stomach ${ }^{(1)}$.

A stroke may be defined as a disturbance in the blood supply to the brain, causing loss or impairment of the respective functions in the cerebral region affected. It may be ischemic, caused by blood vessel obstruction or reduction in the systemic blood flow, or hemorrhagic, caused by the rupture of a weakened blood vessel $^{(2)}$. Recent studies show that the cerebrovascular disease is considered among the main causes of death in Brazil and worldwide $^{(3)}$. In the emergency room, the patient undergoes a neurological evaluation and complementary exams to confirm the diagnosis, type of stroke, and the extent of damage to the cerebral area affected. The initial neurological evaluation includes the application of the National Institute of Health Stroke Scale (NIHSS) ${ }^{(4)}$, which encompasses evaluation of the levels of consciousness, visual field, facial miming, motor power, ataxia, language, dysarthria, and awareness. With a score ranging from 0 to 42 , with higher scores related to increased stroke severity and worse prognosis ${ }^{(5)}$, the scale is used to determine the level of motor impairment resulting from the neurological injury. Although the NIHSS presents predictive characteristics for dysphagia, it is not sufficiently sensitive to be used independently for initial treatment of the disorder ${ }^{(5)}$, hence complementary Speech Language Pathology (SLP) assessment is required.

The incidence of OD in cerebrovascular disease has been documented with variation from $40 \%$ to $90 \%{ }^{(3)}$. OD as a result of stroke is the major cause of death related to breathing complications and malnutrition presented by patients ${ }^{(1)}$. Recent studies have shown that OD is exceedingly common after stroke, especially in the days following the event, with incidence ranging from $18 \%$ to $81 \%$ in the acute phase and prevalence of $12 \%$ among patients ${ }^{(6)}$.

A review of the literature shows high incidence of dysphagia in the acute phase of stroke, independent of the localization of the injury, which indicates the need for SLP assessment in such cases ${ }^{(7)}$. Clinical SLP evaluation is based on the patient's account and on a physical examination guided towards problems of swallowing, communication, evaluation of the anatomy, functionality and sensibility of orofacial structures, and testing of food oral ingestion ${ }^{(8)}$.

Determination of the relationship between neurological impairment from stroke and OD will enable emergency care professionals to quickly identify dysphagia in case of positive association between stroke severity (NIHSS), type of stroke, and OD.

The objective of this study is to investigate the relationship between alterations in the swallowing process, stroke severity (NIHSS score), and types of stroke.

\section{METHODS}

This is a cross-sectional, descriptive study conducted with patients hospitalized in the Neurologic Department of the "Irmandade Santa Casa de Misericórdia de Porto Alegre" (ISCMPA) between January and August 2013. The present study was approved by the Research Ethics Committee of the ISCMPA under protocol number 41354/12. All study participants or their legal guardians have signed an Informed Consent Form.

The sample consisted of 42 patients ( 22 women and 20 men), aged 20 to 86 years (mean age $=65.7 \pm 14.4$ years). Individuals included in the study met the following criteria: patients experiencing their first cerebrovascular event hospitalized with clinical symptoms suggestive of stroke and with diagnosis confirmed by cranial computed tomography (CCT) and/or magnetic resonance imaging (MRI).

Upon hospital admission, the patients underwent a clinical neurological evaluation which included a general physical examination, a neurological examination, and the application of the NIHSS in the first 48 hours after stroke. The NIHSS was used to assess the neurological status of patients according to the following scores: 0-6 was considered as minor stroke; 7-15, as moderate stroke, and $\geq 16$, as severe stroke $e^{(9)}$. The scale used in the assessment of stroke severity was chosen because of its routine usage in the neurology department of the Institute. The literature shows other classifications as more commonly used $^{(10)}$; however; a choice was made for the method already in use and the results were correlated with the evaluations of the swallowing process.

Clinical evaluation of the swallowing process was then performed through the application of the Protocol for Investigation of Oropharyngeal Dysphagia in Adults ${ }^{(11-14)}$. The assessment consisted in the evaluation of the orofacial myofunctional system, verification of structure strength and mobility, lower airway protection mechanisms, presence of vocal alterations, and the patient's state of awareness. It was followed by the direct swallowing test, which was prepared with sequential offerings of varying consistencies. The test was initiated with offerings of pasty consistency served in portions of increasing sizes $(1 / 3,1 / 2,1,3$ and 5 tablespoons), followed by liquid $(3,5,10,20$ and $50 \mathrm{ml}$ of distilled water), and finally solids ( 5 small pieces of bread). The direct swallowing test was conducted according to the recommendations provided to each patient by a nutritionist. The three consistencies were evaluated sequentially, with progression to each stage of evaluation dependent on the patient's performance in the previous stage. If the patient presented alterations in the evaluation of a certain consistency, the test was interrupted and the remaining consistencies were not offered. Swallowing, involuntary cough, presence of excessive salivation, and dysphonia were 
evaluated. The severity of oropharyngeal dysphagia scale was graded according to the Gugging Swallowing Screen (GUSS) ${ }^{(13)}$, a score of 0-9 was considered as severe dysphagia; $10-14$, as moderate dysphagia; $15-19$, as mild dysphagia; and 20, as normal deglutition.

Subsequently, the Functional Oral Intake Scale (FOIS) ${ }^{(15)}$ was applied, classifying food intake into a seven-point ordinal scale: 1 (nothing by mouth); 2 (tube dependent with minimal attempts of food or liquid); 3 (tube dependent with consistent oral intake of food or liquid); 4 (total oral diet of a single consistency); 5 (total oral diet with multiple consistencies, but requiring special preparation or compensations); 6 (total oral diet with multiple consistencies without special preparation, but with specific food limitations); and 7 (total oral diet with no restrictions). These levels classify patient food intake either by nasogastric tube or orally.

A swallowing evaluation using the Protocol for the Investigation of Oropharyngeal Dysphagia in Adults was performed within 7 days (mean $=4 \pm 1.91$ days) following the neurological event. The NIHSS conducted by a neurologist on the day of the swallowing evaluation was used in the correlation analysis between stroke severity and dysphagia severity.

\section{Statistics}

The Statistical Package for the Social Sciences (SPSS 12.0, Chicago, IL, USA) was used in data analysis.

The Fisher's Exact Probability Test was utilized to verify the correlation between the degree of biomechanical impairment during swallowing, stroke severity (NIHSS), type of neurological injury, and region of cerebral circulation affected. For this study, results of the statistical analysis were considered significant when $p \leq 0.05$.

\section{RESULTS}

In the sample studied, OD was more frequent among patients aged 60 years and older $(69.0 \%)$. In relation to the types of stroke, 39 patients $(92.9 \%)$ presented ischemic stroke. A profile of the sample description is shown in Table 1.

In the evaluation of the swallowing process, 17 cases (40.5\%) presented severe dysphagia according to the Protocol for Investigation of Oropharyngeal Dysphagia in Adults ${ }^{(11-14)}$.

Table 1. Demographic and clinical characteristics of stroke in patients

\begin{tabular}{lcr}
\hline \multicolumn{1}{c}{ Variable } & Number of cases & $\%$ \\
\hline Age (years) & & \\
$\quad<60$ & 13 & 31.0 \\
$\quad>60$ & 29 & 69.0 \\
Gender & & \\
$\quad$ Female & 22 & 52.4 \\
Type of stroke & & \\
$\quad$ Ischemic & 39 & 92.9 \\
$\quad$ Hemorrhagic & 1 & 2.4 \\
$\quad$ Ischemic stroke with & 2 & 4.8 \\
$\quad$ Hemorrhagic transformation & & \\
\hline
\end{tabular}

Of these 17 patients, $16(31.8 \%)$ were classified as level 1 (nothing by mouth) on the FOIS scale. Regarding the degree of neurological impairment, 17 patients $(40.5 \%)$ presented minor stroke according to the NIHSS, with anterior cerebral circulation as the major region affected in 25 cases (59.5\%). Thirty-two patients $(76.2 \%)$ presented some degree of dysphagia regardless of stroke severity (Table 2).

Statistically significant correlation was found between the NIHSS score and the degree of dysphagia $(p=0.016)$. Minor stroke (NIHSS 0-6) was statistically associated with normal swallowing and mild dysphagia; whereas severe stroke (NIHSS $\geq 16$ ) was statistically associated with severe dysphagia. Furthermore, all patients with NIHSS score $\geq 16$ (severe stroke) presented some degree of OD (Table 3).

It was possible to observe that of the nine patients with severe stroke (NIHSS $\geq 16$ ), seven $(77.8 \%)$ were classified as level 1 by the FOIS, but this relationship was not statistically significant (Table 4).

\section{DISCUSSION}

Stroke is one of the principal causes of OD and possibly the main cause of death related to respiratory complications and malnutrition. Early Speech-language Pathology (SLP) intervention in patients affected by this disorder is aimed at the rapid identification of OD and, consequently, at the prevention

Table 2. Distribution of patients according to affected region of brain circulation, FOIS scores, NIHSS scores, and swallowing evaluation according to the Protocol for the Investigation of Oropharyngeal Dysphagia in Adults

\begin{tabular}{lcc}
\hline \multicolumn{1}{c}{ Variable } & $\begin{array}{c}\text { Number of cases } \\
\text { (total }=42)\end{array}$ & $\%$ \\
\hline FOIS levels & 16 & 38.1 \\
1 & 2 & 4.8 \\
2 & - & - \\
3 & 1 & 2.4 \\
4 & 7 & 16.7 \\
5 & 7 & 16.7 \\
6 & 9 & 21.4 \\
7 & & \\
Degree of Swallowing Impairment & 10 & 23.8 \\
Normal Deglutition & 5 & 11.9 \\
Mild Dysphagia & 10 & 23.8 \\
Moderate Dysphagia & 17 & 40.5 \\
Severe Dysphagia & & \\
NIHSS & 17 & 40.5 \\
$\quad$ Minor (0-6) & 16 & 38.1 \\
Moderate (7-15) & 9 & 21.4 \\
Severe ( $\geq 16)$ & & \\
Affected region of the brain & & \\
circulation & & \\
Anterior Circulation & 25 & 14.3 \\
Posterior Circulation & 69.5 \\
Anterior and Posterior Circulation & & \\
\hline
\end{tabular}

Caption: NIHSS = National Institute of Health Stroke Scale; FOIS = Functional Oral Intake Scale 
Table 3. Association between degree of swallowing impairment, type of stroke, severity (NIHSS), and affected region of brain circulation

\begin{tabular}{|c|c|c|c|c|c|c|c|c|c|c|}
\hline \multirow{3}{*}{ Variable } & \multirow{3}{*}{ Category } & \multicolumn{8}{|c|}{ Degree of swallowing impairment } & \multirow{3}{*}{$\mathrm{p}$} \\
\hline & & \multicolumn{2}{|c|}{$\begin{array}{c}\text { Normal } \\
\text { Deglutition }\end{array}$} & \multicolumn{2}{|c|}{$\begin{array}{c}\text { Mild } \\
\text { Dysphagia }\end{array}$} & \multicolumn{2}{|c|}{$\begin{array}{l}\text { Moderate } \\
\text { Dysphagia }\end{array}$} & \multicolumn{2}{|c|}{$\begin{array}{c}\text { Severe } \\
\text { Dysphagia }\end{array}$} & \\
\hline & & $\mathrm{n}$ & $\%$ & $\mathrm{n}$ & $\%$ & $\mathrm{n}$ & $\%$ & $\mathrm{n}$ & $\%$ & \\
\hline \multirow{3}{*}{ Type of stroke } & Ischemic & 10 & 100 & 5 & 100 & 8 & 80 & 16 & 94.1 & 0.635 \\
\hline & Hemorrhagic & - & - & - & - & 1 & 10 & - & - & \\
\hline & Ischemic with Hemorrhagic Transfusion & - & - & - & - & 1 & 10 & 1 & 5.9 & \\
\hline \multirow{3}{*}{ NIHSS } & Minor & 7 & 70 & 4 & 80 & 4 & 40 & 2 & 11.8 & $0.016^{\star}$ \\
\hline & Moderate & 3 & 30 & 1 & 20 & 4 & 40 & 8 & 47.1 & \\
\hline & Severe & - & - & - & - & 2 & 20 & 7 & 41.2 & \\
\hline \multirow{3}{*}{$\begin{array}{l}\text { Affected region of } \\
\text { brain circulation }\end{array}$} & Anterior Circulation & 8 & 80 & - & - & 5 & 50 & 12 & 70.6 & 0.083 \\
\hline & Posterior Circulation & 2 & 20 & 3 & 60 & 3 & 30 & 3 & 17.6 & \\
\hline & Anterior and Posterior Circulation & - & - & 2 & 40 & 2 & 20 & 2 & 11.8 & \\
\hline
\end{tabular}

Caption: NIHSS = National Institute of Health Stroke Scale

*significance value $\mathrm{p} \leq 0.05$

Table 4. Association between severity (NIHSS) of stroke, affected region of the brain circulation, and FOIS

\begin{tabular}{|c|c|c|c|c|c|c|c|c|}
\hline \multirow{3}{*}{ Variable } & \multirow{3}{*}{ Category } & \multicolumn{6}{|c|}{ NIHSS } & \multirow{3}{*}{$\mathrm{p}$} \\
\hline & & \multicolumn{2}{|c|}{ Minor } & \multicolumn{2}{|c|}{ Moderate } & \multicolumn{2}{|c|}{ Severe } & \\
\hline & & $\mathrm{n}$ & $\%$ & $\mathrm{n}$ & $\%$ & $\mathrm{~N}$ & $\%$ & \\
\hline \multirow{3}{*}{$\begin{array}{l}\text { Affected region of } \\
\text { the brain circulation }\end{array}$} & Anterior Circulation & 7 & 41.2 & 10 & 62.5 & 8 & 88.9 & 0.197 \\
\hline & Posterior Circulation & 7 & 41.2 & 3 & 18.8 & 1 & 11.1 & \\
\hline & Anterior and Posterior Circulation & 3 & 17.6 & 3 & 18.8 & - & - & \\
\hline \multirow{7}{*}{ FOIS levels } & 1 & 2 & 11.8 & 7 & 43.8 & 7 & 77.8 & NSA \\
\hline & 2 & - & - & 1 & 6.3 & 1 & 11.1 & \\
\hline & 3 & - & - & - & - & - & - & \\
\hline & 4 & - & - & 1 & 6.3 & - & - & \\
\hline & 5 & 4 & 23.5 & 2 & 12.5 & 1 & 11.1 & \\
\hline & 6 & 5 & 29.4 & 2 & 12.5 & - & - & \\
\hline & 7 & 6 & 35.3 & 3 & 18.8 & - & - & \\
\hline
\end{tabular}

Caption: NSA = does not apply the statistical test due to insufficient number of cases;

NIHSS = National Institute of Health Stroke Scale; FOIS = Functional Oral Intake Scale

of clinical complications arising from it in order to reduce hospitalization time ${ }^{(16,17)}$. This study aimed to evaluate post-stroke patients, verifying the degree of biomechanical impairment of the swallowing process to establish diagnostic hypotheses and elaborate a therapeutic response according to the needs and clinical status of the patient.

Cerebrovascular disease is the main cause of death in Brazil and it occurs at a greater rate in people over 60 years old; the risk of stroke rises around this age and doubles at every following decade ${ }^{(14,18)}$. The results observed in this study reinforce the findings in the literature ${ }^{(14,19)}$. In addition to swallowing disorders occurring more frequently among patients older than 60 years (69.0\%), a higher incidence of stroke was observed among women, with $52.4 \%$ of the cases. Studies have shown higher incidence of OD, severity, mortality, and morbidity in women who experience their first stroke $e^{(7,20)}$.

From the 42 patients evaluated, $92.9 \%$ presented ischemic stroke. This high percentage is explained by the prevalence of risk factors that can lead to blood vessel obstruction, causing this kind of stroke ${ }^{(21)}$. One study reported that, from the 30 individuals evaluated, 18 presented ischemic stroke, 2 presented hemorrhagic stroke, and 10 had transitory stroke ${ }^{(22)}$.
Previous studies do not show a relationship between ischemic stroke and dysphagia, describing only suggestive findings of OD after neurological impairment ${ }^{(16,18)}$. However, several studies have indicated that this type of stroke is the most prevalent in the affected population ${ }^{(19,22-24)}$. Similarly, this was also observed in our study with varying degrees of swallowing impairment. The large number of ischemic stroke cases may have been a result of early identification and intervention by the Neurology team, or the loss of patients due to incomplete assessment by staff leading to patients not fulfilling the inclusion criteria.

From the evaluation of the swallowing process conducted using the Protocol for the Investigation of Oropharyngeal Dysphagia in Adults ${ }^{(11-14)}, 40.5 \%$ of the cases presented severe dysphagia, confirming results observed in other studies that show a high incidence of OD post stroke, with especially high incidence in the moderate and severe cases of stroke ${ }^{(16,23,25-27)}$. In a previous study, of the 212 stroke patients, $134(63 \%)$ presented OD, with OD classified as mild in 26 patients $(19 \%)$, moderate in $51(38 \%)$, and severe in $57(43 \%)^{(23)}$. In this study, there was a statistically significant correlation between the NIHSS score and the degree of swallowing impairment $(p=0.016)$, with minor stroke being associated with normal swallowing and 
mild dysphagia, whereas severe stroke was associated with severe dysphagia.

Additionally, evaluation of the swallowing process showed that $38.1 \%$ of patients were classified as level 1 (nothing by mouth) on the FOIS. This fact emphasizes the inability of these patients to ingest substances orally prior to SLP intervention. In this study, of the nine patients with severe stroke (NIHSS $\geq 16$ ), seven $(77.8 \%)$ were classified as level 1 on the FOIS; however, this relationship was not found to be statistically significant. A high incidence of post-stroke patients classified as level $1^{(15)}$ presenting more serious neurological impairments was observed in both the present and other studies.

Independent of the stroke severity, $76.2 \%$ of the cases presented some degree of OD, corroborating similar studies that show a high incidence of OD in the acute phase of stroke, which sometimes remains after this period ${ }^{(1,6)}$. Nevertheless, all patients in this study with NIHSS $\geq 16$ (severe stroke) presented some degree of OD. This may be explained by the severity of the neurological injury. In a previous study, from the 70 patients with severe impairment (NIHSS score $>15$ ), 65 presented poor clinical evolution ${ }^{(9)}$, suggesting the use of the NIHSS as a predictor of outcomes of acute hospitalization ${ }^{(9,28)}$. Some studies have presented the NIHSS score between 11 and 12 as the cut-off point for risk of dysphagia ${ }^{(10)}$. The use of the NIHSS is also suggested as an ideal marker in several studies that addressed the consequences of stroke $e^{(5,9,10,17,24,29)}$. Another study assessed the NIHSS score as a predictor for the use of percutaneous endoscopic gastrostomy (PEG) in hospitalized patients with acute ischemic stroke. Furthermore, it sought to identify a specific cut-off point on the scale to predict the need for PEG. It concluded that an NIHSS score of 16 without evidence of aspiration pneumonia and a NIHSS score of 12 with evidence of aspiration pneumonia can assist in the initial decision to perform PEG in patients with acute ischemic stroke $e^{(10)}$.

Another study aimed to detect swallowing difficulties during the acute phase of stroke by developing an algorithm (based on NIHSS) in order to plan the clinical approach in daily practice pending a more detailed assessment by SLP. Of the 16 patients with dysphagia, 14 (87.5\%) presented NIHSS scores $\geq 12$ and two patients (12.5\%) had scores of 10 and 11 , with significant correlation between the NIHSS scores and the presence of dysphagia. It was concluded that the NIHSS is highly sensitive $(88 \%)$ and specific $(85 \%)$ in relation to dysphagia detection; a score of 12 may be considered as the cut-off point ${ }^{(29)}$.

Although there are studies that indicate a score of $\geq 12$ on the NIHSS as a cut-off point for dysphagia, the present survey was based on a classification system routinely used by the Neurology department of the hospital. This may have caused the loss of some patients due to the specific parameters in the NIHSS used to identify dysphagia.

In the current research, anterior cerebral circulation was the main region affected in 25 cases (59.5\%), agreeing with previous studies that showed higher percentages of dysphagia patients with carotid artery circulation alterations ${ }^{(7,28)}$. In a previous work, the topography of the lesion was significantly correlated to the presence or absence of dysphagia. Deglutition disorder was present in all patients $(100 \%)$ with lesions of the carotid artery ${ }^{(29)}$.

The presence of dysphagia is strongly associated with this subtype of stroke. Patients with lesions in the anterior cerebral circulation have a high incidence of dysphagia within the first week after the incident. When examined more closely, $75 \%$ of these patients experienced dysphagia two days after stroke and $90 \%$ of this subset persist with dysphagia after 1 week $^{(30)}$. Infarctions involving the anterior cerebral artery are primarily responsible for dysphagia, because they affect important areas involved in swallowing ${ }^{(28)}$. There is high prevalence of lesions in the carotid artery; this area was affected in $76 \%$ of patients with dysphagia, although not statistically significant ${ }^{(7)}$.

The present study presents some limitations, such as disproportion in the sample in relation to the type of stroke and localization of the neurological injury. This occurred due to the exclusion of many patients who did not undergo proper assessment to qualify for the study. In addition, the classification criteria of the adopted NIHSS differed from other findings in the literature that show a score $\geq 12$ as the cut-off point for dysphagia and, consequently, led to the loss of some dysphagia patients.

This study aimed to determine the relationship between OD and stroke, to assist health professionals in the early identification of dysphagia in post-stroke patients in the event that a positive correlation was found between stroke severity (NIHSS), type of stroke, and OD.

\section{CONCLUSION}

Association was observed between the result of the NIHSS evaluation and the degree of dysphagia. Consequently, stroke severity was found to be positively correlated with the degree of OD. Statistically significant correlation was observed between minor stroke (NIHSS 0-6), normal swallowing, and mild dysphagia; whereas severe stroke (NIHSS $\geq 16$ ) was statistically correlated to severe dysphagia. There was no statistically significant association between the FOIS and stroke severity (NIHSS). These relationships may allow for early identification of dysphagia by health professionals involved in patient care. Further studies with larger homogeneous samples are needed to determine the association between the degree of biomechanical impairment in the swallowing process and the severity (NIHSS) and type of neurological injury.

\section{REFERENCES}

1. Benvenuti CM, Pereira LM, Revay MA. Disfagia pós-acidente vascular cerebral isquêmico unilateral em adultos: estudo de caso [Thesis]. Florianópolis (SC): Centro de Especialização em Fonoaudiologia Clínica; 2005. 29 p.

2. Damiani IT, Yokoo I. [Internet]. AVC - Acidente Vascular Cerebral. São Paulo: Saúde em Movimento; 2002 [cited 2013 Aug 23]. Available from: www. saudeemmovimento.com.br/conteudos/conteudo print.asp?cod noticia $=44$

3. Singh S, Hamdy S. Dysphagia in stroke patients. Postgrad Med J 2006;82(968):383-91. PMid:16754707. http://dx.doi.org/10.1136/ pgmj.2005.043281.

4. Fábio SRC, Coletto FA, Pontes OM No, Okubo PCMI, Moro CHC, Martins SCO. [Internet]. Rotinas no AVC: pré-hospitalar e hospitalar. Brasília: Ministério da Saúde; 2009 [cited 2013 Jun 15]. Available from: 
http://www.acaoavc.org.br/admin/wp-content/uploads/2015/10/6.3.7rotinas_no_avc_abril_2009.pdf

5. Jeyaseelan RD, Vargo MM, Chae J. National Institutes of Health Stroke Scale (NIHSS) as an early predictor of poststroke dysphagia. PM R. 2015;7(6):5938. PMid:25556573. http://dx.doi.org/10.1016/j.pmrj.2014.12.007.

6. Remesso GC, Fukujima MM, Chiappetta ALML, Oda AL, Aguiar AS, Oliveira ASB, et al. Swallowing disorders after ischemic stroke. Arq Neuropsiquiatr. 2011;69(5):785-9. PMid:22042182. http://dx.doi.org/10.1590/ S0004-282X2011000600012.

7. Barros AFF, Fábio SRC, Furkim AM. Correlação entre os achados clínicos da deglutição e os achados da tomografia computadorizada de crânio em pacientes com acidente vascular cerebral isquêmico na fase aguda da doença. Arq Neuropsiquiatr. 2006;64(4):1009-14. PMid:17221014. http:// dx.doi.org/10.1590/S0004-282X2006000600024.

8. Maccarini AR, Filippini A, Padovani D, Limarzi M, Loffredo M, Casolino D. Clinical non-instrumental evaluation of dysphagia. Acta Otorhinolaryngol Ital. 2007;27(6):299-305. PMid:18320836.

9. Tseng MC, Chang KC. Stroke severity and early recovery after firstever ischemic stroke: results of a hospital-based study in Taiwan. Health Policy. 2006;79(1):73-8. PMid:16406133. http://dx.doi.org/10.1016/j. healthpol.2005.12.003.

10. Alshekhlee A, Ranawat N, Syed TU, Conway D, Ahmad SA, Zaidat OO. National Institutes of Health stroke scale assists in predicting the need for percutaneous endoscopic gastrostomy tube placement in acute ischemic stroke. J Stroke Cerebrovasc Dis. 2010;19(5):347-52. PMid:20554223. http://dx.doi.org/10.1016/j.jstrokecerebrovasdis.2009.07.014.

11. De Angelis EC. Protocolo de avaliação clínica no leito. In: Jotz GP, De Angelis EC, Barros APB. Tratado da deglutição e disfagia: no adulto e na criança. Rio de Janeiro: Revinter; 2009. p. 71-5.

12. Silva RG. Disfagia neurogênica em adultos: uma proposta para avaliação clínica. In: Furkim AM, Santini CRQS, editors. Disfagias orofaríngeas. 2nd ed. Barueri: Pró-Fono; 2008. p. 35-47.

13. Trapl M, Enderle P, Nowotny M, Teuschl Y, Matz K, Dachenhausen A, et al. Dysphagia bedside screening for acute-stroke patients: the gugging swallowing screen. Stroke. 2007;38(11):2948-52. PMid:17885261. http:// dx.doi.org/10.1161/STROKEAHA.107.483933.

14. Schultheiss C, Nusser-Muller-Brusch R, Seidl RO. The semisolid bolus swallow test for clinical diagnosis of oropharyngeal dysphagia: a prospective randomised study. Eur Arch Otorhinolaryngol. 2011;268(12):1837-44. PMid:21607581. http://dx.doi.org/10.1007/s00405-011-1628-5.

15. Crary MA, Mann GD, Groher ME. Initial psychometric assessment of a functional oral intake scale for dysphagia in stroke patients. Arch Phys Med Rehabil. 2005;86(8):1516-20. PMid:16084801. http://dx.doi.org/10.1016/j. apmr.2004.11.049.

16. Abdulmassih EMS, Macedo ED Fo, Santos RS, Jurkiewicz AL. Evolução de pacientes com disfagia orofaríngea em ambiente hospitalar. Int Arch Otorhinolaryngol. 2009;13:55-62.

17. Itaquy RB, Favero SR, Ribeiro MC, Barea LM, Almeida ST, Mancopes R. Disfagia e acidente vascular cerebral: relação entre o grau de severidade e o nível de comprometimento neurológico. J Soc Bras Fonoaudiol.
2011;23(4):385-9. PMid:22231062. http://dx.doi.org/10.1590/S217964912011000400016.

18. Castro JAB, Epstein MG, Sabino GB, Nogueira GLO, Blankenburg C, Staszko KF, et al. Estudo dos principais fatores de risco para acidente vascular encefálico. Rev Bras Clin Med. 2009;7:171-3.

19. Puerari VR. Avaliação clínica precoce da disfagia orofaríngea em pacientes adultos após o acidente vascular encefálico [Thesis]. Porto Alegre (RS): Universidade Federal do Rio Grande do Sul; 2011. 84 p.

20. Rouquer J, Campello AR, Gomis M. Sex differences in first-ever acute stroke. Stroke. 2003;34(7):1581-5. PMid:12805490. http://dx.doi.org/10.1161/01. STR.0000078562.82918.F6.

21. Pires SL, Gagliardi RJ, Gorzoni ML. Estudo das frequências dos principais fatores de risco para acidente vascular cerebral isquêmico em idosos. Arq Neuropsiquiatr. 2004;62(3-B):844-85. PMid:15476081. http://dx.doi. org/10.1590/S0004-282X2004000500020.

22. Nunes MCA, Jurkiewicz AL, Santos RS, Furkim AM, Massi G, Pinto GSP, et al. Correlação entre a lesão encefálica e a disfagia em pacientes adultos com acidente vascular encefálico. Int Arch Otorhinolaryngol. 2012;16:313-21. PMid:25991951.

23. Baroni AFFB, Fábio SRC, Dantas RO. Risk factors for swallowing dysfunction in stroke patients. Arq Gastroenterol. 2012;49(2):118-24. PMid:22766998. http://dx.doi.org/10.1590/S0004-28032012000200005.

24. Moon HI, Pyun SB, Kwon HK. Correlation between location of brain lesion and cognitive function and findings of videofluoroscopic swallowing study. Ann Rehabil Med. 2012;36(3):347-55. PMid:22837970. http://dx.doi. org/10.5535/arm.2012.36.3.347.

25. Daniels SK, Brailey K, Priestly DH, Herrington LR, Weisberg LA, Foundas AL. Aspiration in patients with acute stroke. Arch Phys Med Rehabil. 1998;79(1):14-9. PMid:9440410. http://dx.doi.org/10.1016/ S0003-9993(98)90200-3.

26. Gatto AR, Rehder MIBC. Comparação entre queixas de deglutição e achados videofluroscópicos no paciente pós acidente vascular encefálico. Rev CEFAC. 2006;8:320-7.

27. Pires CV. Avaliação nutricional na admissão do doente com AVC [Thesis]. Bragança (PT): Instituto Politécnico de Bragança; 2012. 96 p.

28. Paciaroni M, Mazzotta G, Corea F, Caso V, Venti M, Milia P, et al. Dysphagia following stroke. Eur Neurol. 2004;51(3):162-7. PMid:15073441. http:// dx.doi.org/10.1159/000077663.

29. Okubo PC, Fábio SR, Domenis DR, Takayanagui OM. Using the National Institute of Health Stroke Scale to predict dysphagia in acute ischemic stroke. Cerebrovasc Dis. 2012;33(6):501-7. PMid:22538772. http://dx.doi. org/10.1159/000336240.

30. Langdon PC, Lee AH, Binns CW. Dysphagia in acute ischemic stroke: severity, recovery and relationship to stroke subtype. J Clin Neurosci. 2007;14(7):6304. PMid:17434310. http://dx.doi.org/10.1016/j.jocn.2006.04.009.

\section{Author contributions}

$D M O$ was responsible for the project design, collection and analysis of data, and scientific development of the study; MCR and LMB contributed to the project design and scientific development of the study; RM and STA contributed to the project design, data analysis, and scientific development of the study. 